\title{
EDUCAÇÃO FÍSICA NA EDUCAÇÃO INFANTIL: UM DEBATE NECESSÁRIO
}

\author{
PHYSICAL EDUCATION IN CHILD EDUCATION: \\ A NECESSARY DEBATE
}

\section{LA EDUCACIÓN FÍSICA EN LA EDUCACIÓN INFANTIL: UN DEBATE NECESARIO}

\author{
Jaíne de Abreu Santos Ribeiro \\ https://orcid.org/0000-0002-6106-2622 (D) \\ http://lattes.cnpq.br/1239939280244118 9 \\ Centro Universitário AGES (Paripiranga, BA - Brasil) \\ jaineeabreu12@gmail.com \\ Davi Soares Santos Ribeiro \\ https://orcid.org/0000-0001-9816-2566 (D) \\ http://lattes.cnpq.br/1157354317014194 9 \\ Centro Universitário AGES (Paripiranga, BA - Brasil) \\ profdavi@live.com \\ Cleiton Antonio de Oliveira \\ https://orcid.org/0000-0002-0502-9262 \\ http://lattes.cnpq.br/5271304914977368 \\ Centro Universitário AGES (Paripiranga, BA - Brasil) \\ cleiton.oliveira@ages.edu.br
}

\section{Resumo}

A educação infantil é a primeira etapa da educação básica pela qual as crianças iniciam o percurso na educação formal e passam a vivenciar novas aprendizagens que potencializam o seu desenvolvimento psicomotor e social, a exemplo da Educação Física. Sendo assim, o presente estudo tem por objetivo discutir a importância da Educação Física na Educação Infantil. Foi utilizada uma pesquisa bibliográfica com abordagem qualitativa. Os resultados apresentaram que apesar da Educação Física ser um componente curricular obrigatório na educação básica, observa-se a ausência na educação infantil. Nesse contexto, torna-se essencial o compromisso ético, político e social dos professores de Educação Física em exigir o cumprimento da LDB, a fim de não perder esse espaço tão importante para a formação cognitiva, social e mental das crianças.

Palavras-chave: Educação Infantil; Educação Física; Professor de Educação Física.

\section{Abstract}

Early childhood education is the first stage of basic education by which children begin their journey in formal education and begin to experience new learning that enhances their psychomotor and social development, such as Physical Education. Therefore, this study aims to discuss the importance of Physical Education in Early Childhood Education. A bibliographic search with a qualitative approach was used. The results showed that although Physical Education is a compulsory curricular component in basic education, there is an absence in early childhood education. In this context, the ethical, political and social commitment of Physical Education teachers to demand compliance with the LDB becomes essential, in order not to lose this space so important for the cognitive, social and mental training of children.

Keywords: Early Childhood Education; Physical Education; Physical Education Teacher.

\section{Resumen}


La educación infantil es la primera etapa de la educación básica por la cual los niños comienzan su viaje en la educación formal y comienzan a experimentar nuevos aprendizajes que mejoran su desarrollo psicomotor y social, como la Educación Física. Por tanto, este estudio tiene como objetivo discutir la importancia de la Educación Física en la Educación Infantil. Se utilizó una búsqueda bibliográfica con enfoque cualitativo. Los resultados mostraron que si bien la Educación Física es un componente curricular obligatorio en la educación básica, existe una ausencia en la educación infantil. En este contexto, el compromiso ético, político y social de los profesores de Educación Física para exigir el cumplimiento de la LDB se torna fundamental, para no perder este espacio tan importante para la formación cognitiva, social y mental de los niños.

Palabras clave: Educación Infantil; Educación Física; Profesor de Educación Física.

\section{INTRODUÇÃO}

A educação infantil é a primeira etapa da Educação Básica em que as crianças iniciam o percurso na educação formal e passam a vivenciar novas aprendizagens que visam potencializar o desenvolvimento bio-psico-sócio-afetivo-cultural.

Segundo a Lei de Diretrizes e Bases da Educação Nacional (LDBEN/96), artigo 29, a Educação Infantil atende crianças de zero a três anos na creche e de quatro e cinco anos na pré-escola e tem como finalidade o desenvolvimento integral da criança em seus aspectos físico, psicológico, intelectual e social, complementando a ação da família e da comunidade (BRASIL, 1998).

Considerando que a infância é uma fase de descobertas, de novas experiências, destaca-se a Educação Física na educação infantil, pois o ensino das práticas corporais proporciona uma diversidade de experiências nas quais as crianças podem criar, inventar, descobrir movimentos novos, reelaborar conceitos e ideias sobre o movimento e suas ações.

As práticas corporais são um conjunto de produções culturais que se expressam pelo corpo, como o futsal, o basquete, a luta marajoara, as danças folclóricas, o atletismo e as demais formas de experiência com o corpo que devem ser tratadas como meios para que os alunos se apropriem paulatinamente nas aulas de Educação Física (FURTADO, 2021) e que possibilitam contribuir no desenvolvimento integral, como possibilidade de relação com ele mesmo e com o mundo que o cerca.

Nesse contexto, a presença do professor de Educação Física torna-se essencial por possibilitar às crianças uma diversidade de experiências por meio de situações nas quais elas possam criar, inventar, descobrir movimentos novos, reelaborar conceitos e ideias sobre o movimento e suas ações (BASEI, 2008).

Entretanto, apesar de ser um componente curricular obrigatório no ensino básico da educação brasileira e, como tal, integra-se à proposta pedagógica das escolas - Lei de 
Diretrizes e Bases da Educação Nacional, 1996, complementada pela Lei n 10.793, de 2003 (BRASIL, 2003), a Educação Física está pouco presente na Educação Infantil.

Nesse contexto, o estudo tem o objetivo de discutir a importância da Educação Física na educação infantil.

\section{METODOLOGIA}

\section{Caracterização do Estudo}

Trata-se de uma pesquisa bibliográfica com abordagem qualitativa. Segundo Lakatos e Marconi (2017), a pesquisa bibliográfica tem como foco o contato direto com materiais e estudos já publicados sobre o assunto, os quais direcionam a pesquisa, tendo assim maior afinidade com o problema delimitado e fazendo levantamento de informações prévias de outros autores sobre o tema.

A abordagem qualitativa, de acordo com Minayo (2016), se preocupa em analisar os aspectos encontrados em uma determinada realidade que não podem ser quantificados, centrando-se principalmente na compreensão e explicação da dinâmica das relações sociais, com o universo de significados, motivos, aspirações, crenças, valores e atitudes dos fenômenos que não podem ser reduzidos à operacionalização de variáveis.

\section{Coleta dos dados}

Para realizar o levantamento bibliográfico foram utilizados livros, artigos científicos encontrados na base de dados do Google Acadêmico e a Legislação Brasileira nos veículos oficiais do Brasil. Utilizou-se os descritores: educação infantil, crianças, professor de Educação Física.

Foram considerados os seguintes parâmetros limitadores da busca inicial: a) artigos, livros e leis publicados entre 1988 e 2020; b) redigidos em língua portuguesa, espanhola ou inglesa; e, c) publicações que tivessem como foco a temática do estudo.

\section{Análise dos dados}

Após levantamento preliminar em artigos, livros ou em bases de dados escolhidas, o conteúdo dos livros e os resumos dos artigos selecionados foram revisados de modo a se refinar a escolha final das publicações que comporiam o corpus deste estudo. 
Nesta etapa foram excluídos livros e artigos que não satisfaziam os critérios de inclusão referidos

\section{RESULTADOS E DISCUSSÃO}

Para discutir a importância da presença da Educação Física na educação infantil, realizou-se uma análise dos aspectos legais que regem essa modalidade de ensino, bem como o processo de regulamentação do profissional de Educação Física.

Quadro 1 - Aspectos legais da Educação Infantil

\begin{tabular}{|c|c|}
\hline DOCUMENTOS LEGAIS & DESCRIÇÃO \\
\hline Constituição Federativa do Brasil de 1988 & $\begin{array}{l}\text { Dispõem que: O dever do Estado com a Educação será } \\
\text { efetivado mediante a garantia de [...] educação infantil, } \\
\text { em creche e pré-escola, às crianças até } 5 \text { (cinco) anos } \\
\text { de idade (Art. 208, inciso IV). }\end{array}$ \\
\hline Lei n$^{\circ} 8.069$, de 13 de julho de 1990 & $\begin{array}{l}\text { Dispõe sobre o Estatuto da Criança e do Adolescente e } \\
\text { dá outras providências. } \\
\text { As crianças de } 0 \text { a } 6 \text { anos de idade deveriam ter direito } \\
\text { de atendimento em creche e pré-escola (Art. 54, inciso } \\
\text { IV). }\end{array}$ \\
\hline Lei n$^{\circ}$ 9.394, de 20 de dezembro de 1996 & $\begin{array}{l}\text { Estabelece as diretrizes e bases da educação nacional. } \\
\text { A educação infantil, primeira etapa da educação básica, } \\
\text { tem como finalidade o desenvolvimento integral da } \\
\text { criança até seis anos de idade, em seus aspectos físico, } \\
\text { psicológico, intelectual e social, complementando a } \\
\text { ação da família e da comunidade (Art. 29). } \\
\text { A educação infantil será oferecida em: I - creches, ou } \\
\text { entidades equivalentes, para crianças de até três anos } \\
\text { de idade; II - pré-escolas, para as crianças de quatro a } \\
\text { seis anos de idade (Art. 30). } \\
\text { Na educação infantil a avaliação far-se-á mediante } \\
\text { acompanhamento e registro do seu desenvolvimento, } \\
\text { sem o objetivo de promoção, mesmo para o acesso ao } \\
\text { Ensino Fundamental (Art. 31). }\end{array}$ \\
\hline $\begin{array}{l}\text { Resolução CEB no 01, de } 07 \text { de abril de } \\
1999\end{array}$ & $\begin{array}{l}\text { Institui as Diretrizes Curriculares Nacionais para a } \\
\text { Educação Infantil. } \\
\text { A educação infantil tem como perspectiva "promover a } \\
\text { educação e o cuidado, promovendo a integração entre }\end{array}$ \\
\hline
\end{tabular}




\begin{tabular}{|c|c|}
\hline & $\begin{array}{l}\text { os aspectos físicos, emocionais, afetivos, } \\
\text { cognitivos/linguísticos e sociais da criança, entendendo } \\
\text { que ela é um ser completo, total e indivisível" (Art. } 3^{\circ}, \\
\text { inciso III). }\end{array}$ \\
\hline Lei $\mathrm{n}^{\circ} 11.274$, de 6 de fevereiro de 2006 & $\begin{array}{l}\text { Altera a redação dos arts. 29, 30, } 32 \text { e } 87 \text { da Lei } n^{\circ} \\
9.394 \text {, de } 20 \text { de dezembro de 1996, que estabelece as } \\
\text { diretrizes e bases da educação nacional, dispondo } \\
\text { sobre a duração de } 9 \text { (nove) anos para o ensino } \\
\text { fundamental, com matrícula obrigatória a partir dos } 6 \\
\text { (seis) anos de idade. }\end{array}$ \\
\hline Lei no 13.005 , de 25 de junho de 2014 & $\begin{array}{l}\text { Aprova o Plano Nacional de Educação - PNE e dá } \\
\text { outras providências. } \\
\text { Meta 1: universalizar, até 2016, a educação infantil na } \\
\text { pré-escola para as crianças de } 4 \text { (quatro) a } 5 \text { (cinco) } \\
\text { anos de idade e ampliar a oferta de educação infantil } \\
\text { em creches de forma a atender, no mínimo, 50\% } \\
\text { (cinquenta por cento) das crianças de até } 3 \text { (três) anos } \\
\text { até o final da vigência deste PNE. }\end{array}$ \\
\hline Lei $n^{\circ} 13.306$, de 4 de julho de 2016 & $\begin{array}{l}\text { Altera a Lei no } 8.069 \text {, de } 13 \text { de julho de } 1990 \text { - Estatuto } \\
\text { da Criança e do Adolescente, a fim de fixar em cinco } \\
\text { anos a idade máxima para o atendimento na educação } \\
\text { infantil. }\end{array}$ \\
\hline $\begin{array}{l}\text { Resolução CNE/CP n 2, de } 22 \text { de } \\
\text { dezembro de } 2017\end{array}$ & $\begin{array}{l}\text { Institui e orienta a implantação da Base Nacional } \\
\text { Comum Curricular, a ser respeitada obrigatoriamente } \\
\text { ao longo das etapas e respectivas modalidades no } \\
\text { âmbito da Educação Básica. }\end{array}$ \\
\hline
\end{tabular}

Fonte: construção dos autores

A educação infantil sofreu algumas mudanças em sua trajetória institucional de atendimento às crianças desde o assistencialismo até a função educacional. Houve avanços obtidos a partir da Constituição de 1988 (BRASIL, 1988) e as promulgações de novas leis, assim como Lei de Diretrizes e Bases da Educação - LDB (1996), porém ainda existem desafios pelos quais a educação infantil tem enfrentado, a exemplo da oferta de creches.

Em relação aos documentos legais da educação infantil, destacam-se a Constituição Federativa do Brasil, a Lei de Diretrizes e Bases da Educação, as Diretrizes Curriculares Nacionais para a Educação Infantil e a Base Nacional Comum Curricular.

A Constituição Federal de 1988 aborda a educação infantil quando afirma em seu artigo 208, que "O dever do Estado com a educação será efetivado mediante a garantia de: 
[...] IV- Atendimento em creche e pré-escola às crianças de zero a seis anos de idade" (BRASIL, 1988).

A Lei $n^{\circ}$ 8.069, de 13 de julho de 1990, dispôs sobre o Estatuto da Criança e do Adolescente e dá outras providências, preconizando que as crianças de 0 a 6 anos de idade deveriam ter direito de atendimento em creche e pré-escola (Art. 54, inciso IV).

Por conseguinte, a Lei de Diretrizes e Bases da Educação Nacional (LDB) cita que a educação infantil tem "[...] como finalidade o desenvolvimento integral da criança até seis anos de idade, em seus aspectos físico, psicológico, intelectual e social, complementando a ação da família e da comunidade" (BRASIL, 1996).

Nesse contexto, as resoluções CEB n 01, de 07 de abril de 1999 e a CNE/CP n² 2, de 22 de dezembro de 2017, instituíram as Diretrizes Curriculares Nacionais para a Educação Infantil e a Base Nacional Comum Curricular, respectivamente (BRASIL, 1999 e 2017).

A partir da modificação introduzida na LDB em 2006, através da Lei 11.274, de 6 de fevereiro de 2006 (BRASIL, 2006) o acesso ao ensino fundamental é antecipado para os 6 (seis) anos de idade, ou seja, para ingressarem para o primeiro ano do ensino fundamental é preciso ter seis anos completos até 31 de março.

O Plano Nacional de Educação (PNE) aprovado pela Lei n 13.005/2014 é um documento que determina as diretrizes, metas e estratégias para a política educacional entre o período de 2014 e 2024. Dentre as vinte metas estabelecidas pelo PNE, destaca-se universalizar, até 2016, a educação infantil na pré-escola para as crianças de 4 (quatro) a 5 (cinco) anos de idade e ampliar a oferta de educação infantil em creches de forma a atender, no mínimo, 50\% (cinquenta por cento) das crianças de até 3 (três) anos até o final da vigência deste PNE (BRASIL, 2014).

Entretanto, segundo dados do Observatório do PNE - OPNE (2018), o Brasil possui 93,8\% de crianças dos 4 e 5 anos de idade na pré-escola, sendo que 6,2\% restantes estão em situações de vulnerabilidade social. E possui 35,7\% de crianças de 0 a 3 anos na educação infantil, ainda não atingindo o objetivo do PNE, que é o de atendimento de $50 \%$ até 2024 .

De acordo com os dados do Censo Escolar de 2018, 103 mil estabelecimentos de ensino ofereciam pré-escola no Brasil, atendendo 5,2 milhões de alunos. Desses, 23\% frequentavam a rede privada. O acesso à pré-escola está próximo da universalização, de acordo com a Pesquisa Nacional por Amostra de Domicílios Contínua (2017), do IBGE. Na 
faixa etária adequada a esta etapa, de 4 e 5 anos, o Censo Escolar mostra que o atendimento escolar já é de 91,7\%, porém na faixa etária de 0 a 3 anos, o atendimento escolar é de 32,7\% (BRASIL, 2019). Os dados revelam a necessidade de investimentos na educação infantil, principalmente nas creches, pois são instituições cruciais no processo de aprendizagem no início da vida.

Por conseguinte, a Lei $n^{\circ} 13.306$, de 4 de julho de 2016 alterou a Lei $n^{\circ}$ 8.069, de 13 de julho de 1990 - Estatuto da Criança e do Adolescente, a fim de fixar em cinco anos a idade máxima para o atendimento na educação infantil (BRASIL, 2016). Vale destacar que a Lei $n^{\circ} 13.306 / 2016$ só veio atualizar o texto do ECA, que antes era de zero a seis anos na educação básica.

Com a Resolução CNE/CP n 2, de 22 de dezembro de 2017 (BRASIL, 2017), a BNCC torna-se um importante documento para o processo histórico da integração da educação infantil ao conjunto da Educação Básica, porém não é mencionada a Educação Física nessa modalidade. Entretanto, a BNCC na educação infantil menciona o campo de experiência "corpo, gestos e movimentos" que aborda aprendizados essenciais na educação de crianças relacionados ao corpo que é competência do professor de Educação Física.

É evidente a contribuição do professor de Educação Física na educação infantil, visto que essa modalidade objetiva o desenvolvimento integral da criança, compreendendo, com isso, os aspectos bio-psico-sócio-afetivo-cultural.

Quadro 2 - Aspectos legais do Profissional de Educação Física

\begin{tabular}{|c|c|}
\hline DOCUMENTOS LEGAIS & DESCRIÇÃO \\
\hline $\begin{array}{l}\text { Lei } n^{\circ} 9.394 \text {, de } 20 \text { de } \\
\text { dezembro de } 1996\end{array}$ & 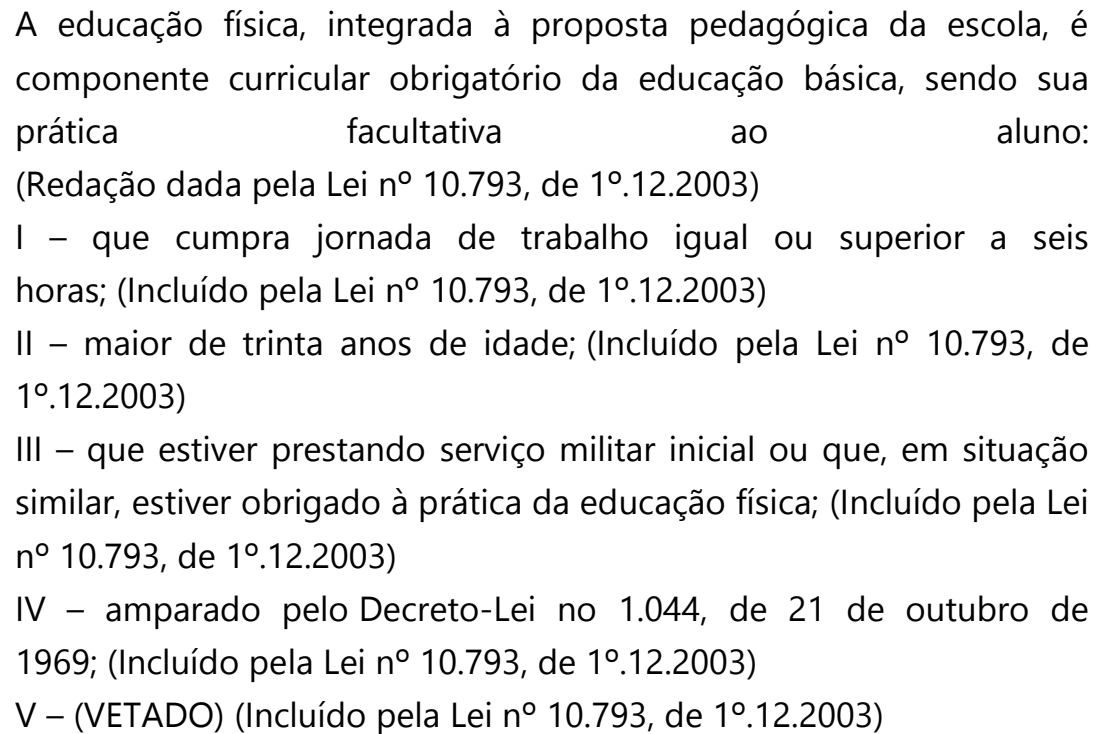 \\
\hline
\end{tabular}




\begin{tabular}{|c|c|}
\hline & $\begin{array}{l}\left.\text { VI - que tenha prole. (Incluído pela Lei } n^{\circ} 10.793 \text {, de } 1^{\circ} .12 .2003\right) \_(\text {Art. } \\
\left.26, \S 3^{\circ}\right) \text {. }\end{array}$ \\
\hline $\begin{array}{l}\text { Lei } n^{\circ} 9696 \text {, de } 1^{\circ} \text { de } \\
\text { setembro de } 1998\end{array}$ & $\begin{array}{l}\text { Dispõe sobre a regulamentação da Profissão de Educação Física e cria } \\
\text { os respectivos Conselho Federal e Conselhos Regionais de Educação } \\
\text { Física. } \\
\text { Compete ao Profissional de Educação Física coordenar, planejar, } \\
\text { programar, supervisionar, dinamizar, dirigir, organizar, avaliar e } \\
\text { executar trabalhos, programas, planos e projetos, bem como prestar } \\
\text { serviços de auditoria, consultoria e assessoria, realizar treinamentos } \\
\text { especializados, participar de equipes multidisciplinares e } \\
\text { interdisciplinares e elaborar informes técnicos, científicos e } \\
\text { pedagógicos, todos nas áreas de atividades físicas e do desporto (Art. } \\
3^{\circ} \text { ). }\end{array}$ \\
\hline $\begin{array}{l}\text { Lei } \mathrm{n}^{\circ} 10.328 \text {, de } 12 \text { de } \\
\text { dezembro de } 2001\end{array}$ & $\begin{array}{l}\text { Introduz a palavra "obrigatório" após a expressão "curricular", } \\
\text { constante do § } 30 \text { do art. } 26 \text { da Lei n 9.394, de } 20 \text { de dezembro de } \\
\text { 1996, que estabelece as diretrizes e bases da educação nacional. }\end{array}$ \\
\hline $\begin{array}{l}\text { Resolução CONFEF n 232, } \\
\text { de } 31 \text { de janeiro de } 2012\end{array}$ & $\begin{array}{l}\text { Dispõe sobre Especialidade Profissional em Educação Física Escolar } \\
\text { A Especialidade Profissional em Educação Física Escolar qualifica o } \\
\text { Profissional Licenciado em Educação Física para o exercício } \\
\text { profissional nos diferentes níveis da Educação Básica, quais sejam, } \\
\text { Educação Infantil, Ensino Fundamental e Ensino Médio (Art. } 3^{\circ} \text { ). }\end{array}$ \\
\hline
\end{tabular}

Fonte: construção dos autores

No que se refere a atuação do Professor de Educação Física na educação infantil, vale destacar que conforme o artigo 26, inciso $3^{\circ}$, da LDB 9.394/96, "a Educação Física é componente curricular da Educação Básica", a qual compreende a Educação Infantil, o Ensino Fundamental e o Ensino Médio (BRASIL, 1996).

Em 2001, na tentativa de garantir a presença da Educação Física em toda a Educação Básica, a Lei no 10.328/2001 (BRASIL, 2001) introduziu o termo "obrigatório" ao artigo 26, inciso $3^{\circ}$ da LDB 9.394/96 (BRASIL, 1996), salvo a sua prática facultativa ao aluno, conforme a Lei $n^{\circ}$ 10.793/2003 (BRASIL, 2003).

A Lei 9.696/98 foi um marco com a regulamentação da Profissão de Educação Física que estabeleceu e modificou o foco da atividade física, da estética e modismo para sinônimo de cultura, vida saudável, desenvolvimento humano e inclusão social.

Nesse contexto, para atuar com a Educação Física, disciplina obrigatória na educação básica, torna-se necessário a graduação em Licenciatura em Educação Física e, assim, contribuir no desenvolvimento bio-psico-sócio-afetivo-cultural das crianças e adolescentes. 


\section{CONSIDERAÇÕES FINAIS}

A educação infantil é uma modalidade da educação básica que visa fornecer às crianças os meios essenciais para o desenvolvimento integral de suas capacidades fundamentais de acordo com suas necessidades físicas e psicológicas. Ao analisar os aspectos legais, observou-se que a educação infantil é um direito da criança, bem como a Educação Física é componente curricular obrigatório na educação básica.

Nesse contexto, torna-se essencial o compromisso ético, político e social dos professores de Educação Física em exigir o cumprimento da LDB, a fim de não perder esse espaço tão importante para a formação cognitiva, social e mental das crianças.

\section{REFERÊNCIAS BIBLIOGRÁFICAS}

BASEl, Andréia Paula. A educação física na educação infantil: a importância do movimentar-se e suas contribuições no desenvolvimento da criança. Revista iberoamericana de educación, v. 47, n. 3, p. 1-12, 2008.

BRASIL. Base Nacional Comum Curricular. Brasília, DF: MEC, 2017. Disponível em: <http://basenacionalcomum.mec.gov.br/>. Acesso em: 14 nov. 2020.

. Constituição da República Federativa do Brasil. Brasília, DF: Senado Federal, Centro Gráfico, $1988 . \quad$ Disponível em <http://www.planalto.gov.br/ccivil_03/constituicao/constituicaocompilado.htm>. Acesso em: 12 nov. 2020.

Emenda constitucional $n^{\circ}$ 59, de 11 de novembro de 2009. Diário Oficial da União, Brasília, DF, 12 de novembro de 2009, Seção 1, p. 8. Disponível em: <http://www.planalto.gov.br/ccivil_03/constituicao/emendas/emc/emc59.htm>. Acesso em: 04 dez. 2020.

Dados do Censo Escolar (20191): número de matrículas na educação infantil cresceu 11,1\% de 2014 a 2018. Brasília, DF: Instituto Nacional de Estudos e Pesquisas Anísio Teixeira Disponível em: <http://portal.inep.gov.br/artigo//asset_publisher/B4AQV9zFY7Bv/content/dados-do-censo-escolar-numero-de-matriculasna-educacao-infantil-cresceu-11-1-de-2014-a-2018/21206>. Acesso em: 13 nov. 2020.

Estatuto da Criança e do Adolescente. Lei 8.069 de 1990. Disponível em: <http://www.planalto.gov.br/ccivil_03/leis//8069.htm>. Acesso em: 13 nov. 2020.

Lei de Diretrizes e Bases da Educação Nacional. Lei n 9.394. Constituição Brasil Brasília, DF, 1998. Disponível em <http://www.planalto.gov.br/ccivil_03/leis//9394.htm>. Acesso em: 13 nov. 2020. 
Lei $n$ 8.742, de 7 de dezembro de 1993. Disponível em <www.planalto.gov.br/ccivil_03/leis/l8742compilado.htm>. Acesso em: 13 nov. 2020.

LEI No 10.793, de $\mathbf{1}^{\circ}$ dezembro 2003. Disponível em <http://www.planalto.gov.br/ccivil_03/leis/2003/L10.793.htm>. Acesso em: 13 nov. 2020.

Ministério da Educação e do Desporto. Secretaria de Educação Fundamental. Referencial curricular nacional para a educação infantil. Brasília, DF: MEC/SEF, 1998. Disponível em: <http://portal.mec.gov.br/seb/arquivos/pdf/rcnei_vol1.pdf>. Acesso em: 25 nov. 2020.

Ministério da Educação. Plano Nacional da Educação. 2014. Disponível em: <http://pne.mec.gov.br>. Acesso em: 28 out. 2020.

FURTADO, Renan Santos. Práticas corporais e educação física escolar: sentidos e finalidades. Corpoconsciência, v. 24, n. 3, p. 156-167, 2020.

LAKATOS, Eva Maria; MARCONI, Marina. Metodologia do trabalho científico: procedimentos básicos, pesquisa bibliográfica, projeto e relatório, publicações e trabalhos científicos. 8. ed. São Paulo: Atlas, 2017

MINAYO, Maria Cecília de Souza: Pesquisa social: teoria, método e criatividade. Petrópolis, RJ: Vozes, 2016.

OPNE. Observatório do PNE. Disponível em: <https://www.observatoriodopne.org.br/>. Acesso em: 22 nov. 2020.

\section{Dados da primeira autora:}

Email: jaineeabreu12@gmail.com

Endereço: Rua Cônego Filadelfo Macedo, 231, Centro, Simão Dias, SE, CEP 49480-000, Brasil.

Recebido em: 29/12/2020

Aprovado em: 09/03/2021

\section{Como citar este artigo:}

RIBEIRO, Jaíne de Abreu Santos; RIBEIRO, Davi Soares Santos; OLIVEIRA, Cleiton Antonio de. Educação física na educação infantil: um debate necessário. Corpoconsciência, v. 25, n. 1, p. 64-73, jan./ abr., 2021. 